\section{Algorithmic Cultures: A Missing Link of Spatial Citizenship Education}

Gl_Forum 2021, Issue 2 Page: 54 - 64

Full Paper

Corresponding Author: edu@leon.fuchs.contact

DOI: 10.1553/giscience2021_02_s54

\author{
Leon Fuchs, Detlef Kanwischer and Christian Dorsch \\ Goethe University Frankfurt/Main, Germany
}

\begin{abstract}
This article addresses the current challenges for geographical educational science brought about by algorithmic cultures. It argues from different theoretical perspectives. First, we discuss sociological, cultural and geographical perspectives on algorithmic cultures and link them to selected approaches of media education in general and geographical media education in particular. We conclude from the discussion that Spatial Citizenship Education is especially suitable to address the challenges. This leads to the question of what aspects of Spatial Citizenship Education need to be supplemented to address algorithmic cultures. We therefore examined the curriculum of Spatial Citizenship Education. The analysis demonstrated that the approach is a sound basis for coping with the developments seen in the context of algorithmic cultures. Nevertheless, algorithmic cultures are accompanied by some changes in social and geographical structures that have not yet been captured by the approach. For example, there is no consideration of geomedia as algorithmic, semiautonomous systems. Further implications also emerge. In this context, the investigation into the practicability and relevance of algorithmic cultures for the practical learning process is of particular interest.
\end{abstract}

\title{
Keywords:
}

algorithms, spatial citizenship education, geography, digital sovereignty

\section{Introduction: Black boxes, sovereignty and education}

Algorithms can be defined as sets of rules that control the behaviour of machines or people. The simplest algorithms, such as rules of behaviour, commandments and laws, have shaped human history from the beginning. Stalder (2018) argues that in digital conditions, algorithmicity has become the distinctive cultural form of expression: 'Faced with the enormous amount of data generated by people and machines, we would be blind were it not for algorithms' (Stalder, 2018: 6). We understand algorithms as decision-making systems based on machine learning neural networks. These kinds of algorithmic assemblages are characterized by recursive operations that allow the systems to develop themselves iteratively (Patterson \& Gibson, 2017). Although the individual algorithms of the systems still follow specific rules of behaviour, by influencing each other a distinct constellation of individual algorithms can morph into a (semi-)autonomous system regarding situated decision-making. 
As a result, these algorithmic assemblages shape infrastructures, practices and daily life around the world. For example, the specific algorithms of various social networks determine the spatial information we receive as well as when and where we receive it. Therefore, algorithms configure the informational basis of our spatial actions. The problem is that in most cases algorithms are black boxes. An algorithm's manner of functioning is known only to the organization that uses it. Sometimes, it is not even known to them. Consequently, our actions are shaped by rules we do not know. Nor do we know what happens to the digital data we produce. As '[a]lgorithms are part of a broader array of performativities that includes, for example, rituals, narratives, and symbolic experiences' (Rauer, 2016: 142), we use the term 'algorithmic cultures'.

Seyfert and Roberge (2016: 6) stated that

instead of treating algorithms as mere utilitarian devices, the study of algorithmic
cultures [...] identifies the meaningfully performative effects that accompany
algorithmic access to the world: What is it that they do, culturally speaking? How
do they make sense of their surroundings and the different categories people use to
interpret them?

From the perspective of geographical media education, the examination and discussion of algorithmic cultures represent a new central topic, as algorithms not only influence students' everyday lives but also shape political and geographical discussions. Every individual requires certain abilities to ensure their digital sovereignty. Gryl et al. (2020) therefore view it as a responsibility of formal education to introduce students to algorithmic cultures at an early stage. Dorsch and Kanwischer (2020) underline the importance of harnessing the potential of digital cultures for educational processes. This should enable pupils, university students and teachers to reflect on algorithms as entities that shape their daily lives. In this context, personal confrontation with algorithms is of particular relevance for the anchoring of algorithmic cultures in educational processes. On the educational level, this is not completely new: we can draw on a variety of approaches that have been developed and introduced in media education and geographical education in recent years. One of the most important approaches is Spatial Citizenship Education (Gryl \& Jekel, 2012; Schulze et al., 2015). The spatial citizen is able to initiate social discourses with the help of digital geomedia. In this way, citizens should be empowered to take ownership of public spaces and to participate in spatial planning processes. The unreflective and merely technical-methodological use of digital geomedia that is frequently observed in geography education has led Gryl, Jekel, Schulze et al. to conceptualize the Spatial Citizenship approach, which is based on a constructivist view of geomedia and learning. In recent years, the approach has been widely adopted in geography education on both theoretical and practical levels. This was accompanied by the continuous development of the approach against the background of technological developments, social changes in everyday life, theoretical aspects, and target-group-specific criteria. However, so far there has been no consideration of geomedia as algorithmic, semi-autonomous systems, as described, for example, in the GIS\&T Body of Knowledge (gistbok.ucgis.org). In other words, a concrete confrontation and examination of algorithmic cultures is a missing link.

This marks the starting point of our contribution, which addresses in particular the following questions. What challenges do algorithmic cultures pose for geography education processes? 
Building on that question: what content-related aspects of Spatial Citizenship Education need to be supplemented in order to address algorithmic cultures? To answer these questions, we will first outline central developments for the appearance of algorithmic cultures and analyse them from a geographical perspective. Based on the results, various media education concepts will be presented. These will provide starting points for integrating algorithmic cultures in educational processes. The approach of Spatial Citizenship Education will also be related to the results. Finally, we will draw a brief conclusion.

\section{Sociological, cultural and geographical perspectives on algorithms}

While computer science and informatics view algorithms primarily in utilitarian terms, social and cultural studies focus on the consequences and meanings that algorithms have for the relationships between technology, humans and society. Seyfert and Roberge (2016: 4) state: 'Indeed, a cultural sociology of the algorithm is possible only insofar as algorithms are considered as both meaningful and performative, that is to say, performative for the very reason that they are meaningful, and vice versa.' Thus, algorithms do not have a causal effect on culture but determine - to use Foucault's term - its dispositifs. In this sense, algorithms not only aggregate, select and produce digital data, but also generate cultural identities. They do this in a variety of ways. As digital gatekeepers, algorithms curate cultural artefacts (e.g. social media posts), and thereby assume the roles of human curators, like art patrons or newspaper critics. Through the attribution of popularity and the creation of trending lists, algorithms construct trends within certain (sub-)publics, which are not usually transparently delimited. Recommendations of trends within digital services, with the help of recommendation systems, can contribute to the creation of filter bubbles and echo chambers (Gillespie, 2016), i.e. the sorting of personal newsfeeds, e.g. on social media platforms, according to the user's preferences assumed by algorithms.

The co-constitutive character of algorithmic systems and the dynamic flow of agency complicate the categorization of roles that algorithms play in socio-cultural processes. As a guide to the different roles, Figure 1 outlines the continuum between social and technological determinism from a geographical perspective.

\begin{tabular}{|lrr|}
\hline $\begin{array}{c}\text { Algorithms as technical tools } \\
\text { in geography }\end{array}$ & $\begin{array}{c}\text { Algorithms as agents } \\
\text { of infrastructure }\end{array}$ & $\begin{array}{c}\text { Algorithms as configurators } \\
\text { of spatial practices }\end{array}$ \\
$\begin{array}{c}\text { Social } \\
\text { determinism }\end{array}$ & & Technological \\
determinism
\end{tabular}

Figure 1: The role of algorithms in socio-technical systems from a geographical perspective (own figure).

The three areas are not to be understood as discrete or strictly delineated classifications but as signposts for orientation within the continuum. The presumed impact of algorithms on human action and social practices increases from left to right. The exact location of the algorithm in the schema depends on the particular situation and the actor who is confronted with it. For 
example, a student who has the ability to understand and reflect on the impact of algorithms on his or her behaviour might handle an algorithm-induced situation in a more competent way than a novice.

\section{Algorithms as technical tools in geography}

The evaluation of satellite data is an example of how algorithms and machine-learning systems are used as geographic tools (Ash et al., 2019, Brandt et al., 2020). With the help of highresolution images, image recognition systems can be trained to determine different landscape forms and surface conditions. Thus, they replace manual classifications by geographers and become a decisive component of the gaining of geographical knowledge. When algorithms are being used as tools, the use of automated image recognition software also changes geographical research practice. This leads to algorithms becoming agents of infrastructures that support action.

\section{Algorithms as agents of infrastructure}

Kitchen and Dodge (2011: 16) developed the term 'code/space' to describe algorithms as part of agents of infrastructure: 'Code/space occurs when software and the spatiality of everyday life become mutually constituted, that is, produced through one another.' The fact that code is written explicitly for the production of space and that algorithmic systems are entering spatial planning processes as carriers of action becomes particularly clear in the example of smart cities. Against the background of the smart city, cities and urban planning concepts are being developed in which algorithms are closely interwoven with urban infrastructure. Algorithms are thus increasingly finding their way into the management of spatial usage data within the city. Analogous to code/space, space and algorithms thus constitute each other.

\section{Algorithms as configurators of spatial practices}

Bots are another example of the dominance of algorithmic cultures in the urban environment. For example, in the context of protest cultures, bots are programmed to collect digital warnings from citizens about ticket inspections on public transport and to disseminate them via Twitter. With the help of these alerts, other passengers on public transport can locate ticket controls roughly and avoid them (Krempl, 2020). This type of bot exemplifies how algorithms can influence and transform communication and mobility practices.

Social transition processes in the geographical context of algorithmic cultures also place new demands on the design and orientation of geography education and learning processes, which are explained below.

\section{Media education, geography and algorithmic cultures}

Concerning educational processes, the influences of algorithms unfold in two ways. On the one hand, algorithms have an impact on educational processes. They can serve as digital tools for the innovation of teaching situations (e.g. learning analytics software) for teachers and learners. In addition, they confront students in their role as decision-makers (e.g. in social networks) with indeterminacy and therefore offer occasions for creative debates, which in turn 
can initiate learning processes. On the other hand, algorithms represent a content-related subject area that has to be made relevant for educational processes in subject-specific contexts.

In the German-language debate on how educational processes can be beneficial in the digital society, the approach of structural media education (Strukturale Medienbildung) by Jörissen and Marotzki (2009) has been widely adopted, and further developed over the years. The approach assumes that media determine the structures of worldviews on a fundamental level. This means that we do not react to media and algorithms but behave as part of them. In this sense, media education is defined as the structural changes in patterns of reference to oneself, and to the world, brought in by the media. Consequently, this change in the defining form of media (as is currently happening with the shift from the 'Gutenberg Galaxy' to the 'Internet Galaxy') also necessitates the development of new conceptual forms of media education, including ones which focus on dealing with indeterminacy in educational and subjectification processes. Therefore, media education cannot be reduced to a 'know-what' and 'know-how' basis. The concept (with reference to Kant) draws special attention to critical analysis of, and autonomous reflection on, knowledge-, action-, boundary- and biography-related aspects of human life (Jörissen \& Marotzki, 2009: 30-32). When media education is transferred to algorithmic cultures in geography education processes, the following reflexive orientation dimensions result:

1. Reflection on the terms and limits of knowledge (e.g., on the question of how algorithms make multiple and different spatial interpretations possible).

2. Reflection on the moral consequences of one's actions that result from concrete social contexts (e.g., when the focus is on spatial options for action carried out through the use of algorithms).

3. Reflection on boundaries as the fundamental structure of education when algorithms reconfigure the relationship between subject and space.

4. Reflection on the process of creating a biography when the question of one's socio-spatial identity and its biographical conditions become virulent in the context of algorithms.

These four dimensions of orientation and reflection provide a means for individuals to grasp and assess the power of digital geomedia and the algorithms involved as channels that structure reality in, and deliver it to, the world. However, at the same time, these dimensions can also serve as an analysis matrix for investigating individual uses and the effectiveness of algorithms regarding educational purposes.

Allert and Richter (2017: 28) also place confronting indeterminacy at the centre of media education, but at the same time understand educational processes as being interwoven in inherently indeterminate social practices that are constantly in the process of being constituted. This relational understanding of education in the context of social practice goes beyond Jörissen and Marotzki's (2009) third dimension (reflection on boundaries), which results in the idea of the autonomous subject being relativized. Therefore, learners are, rather, semiautonomous subjects in the educational process. This gives additional relevance to the abilities of creativity and resistance. A concrete example in the context of algorithms and social networks is the protection of privacy from the state and commercial interests. 
Geographical media education has taken up these approaches in recent years. The effects of algorithmic cultures are approached in different ways. Kanwischer and Schlottmann (2017) and Reithmeier and Kanwischer (2020) show how digital spatial constructions in social networks can find their way into geographic education processes against the background of structural media education. Dorsch and Kanwischer (2020) and Gryl et al. (2020), on the other hand, approach algorithmic cultures via the various dimensions of maturity-oriented education and its relevance for educational processes in the context of digital conditions (Stalder, 2018). However, individual phenomena of algorithmic cultures are mostly dealt with by way of example. A systematic approach in terms of content, starting from algorithmic cultures, which generates subject-specific, subject-didactic and pedagogical discussions, is still lacking. For a concretization and systematization from a geographical perspective, the Spatial Citizenship approach is a good choice.

\section{Spatial Citizenship and algorithmic cultures}

The Spatial Citizenship approach (Gryl \& Jekel, 2012) focuses on the role of the 'spatial citizen' and his or her appropriation of the spatial area for social life. A spatial citizen should know how to navigate everyday life in relation to the physical world, know the meanings associated with the physical objects and the environment, and, eventually, understand the balance of power involved in the production of meaning. The approach includes geotechnologies and related tools for assigning meaning, and newer forms of collaboration and negotiation using Web 2.0 applications. The Spatial Citizenship competence model (Schulze et al., 2015) presents an individual's overall competence as an overlapping arrangement of discrete dimensions of subject-specific as well as generic competences.

The model consists of six major dimensions: 'Technology and Methodology', 'Reflection' and 'Communication', which represent instrumental and interpersonal competences, and form the core competences, or nucleus, of the Spatial Citizenship competence model. These three dimensions include the generic ability to apply technical knowledge and skills using web-2.0based geomedia reflectively. Additionally, the 'spatial citizen' is able to communicate alternative spatial visions and constructions autonomously and collaboratively. The dimensions 'Spatial Domain' and 'Citizenship Education Domain' provide theoretical aspects in content knowledge areas. They are thus related to subject-specific competences and underpin the core competences. Finally, the dimension 'Implementation Strategies' functions as a framing category necessary to link teachers' pedagogical content knowledge and motivational orientations of teaching and learning to the field of Spatial Citizenship (Schulze et al., 2014a). 


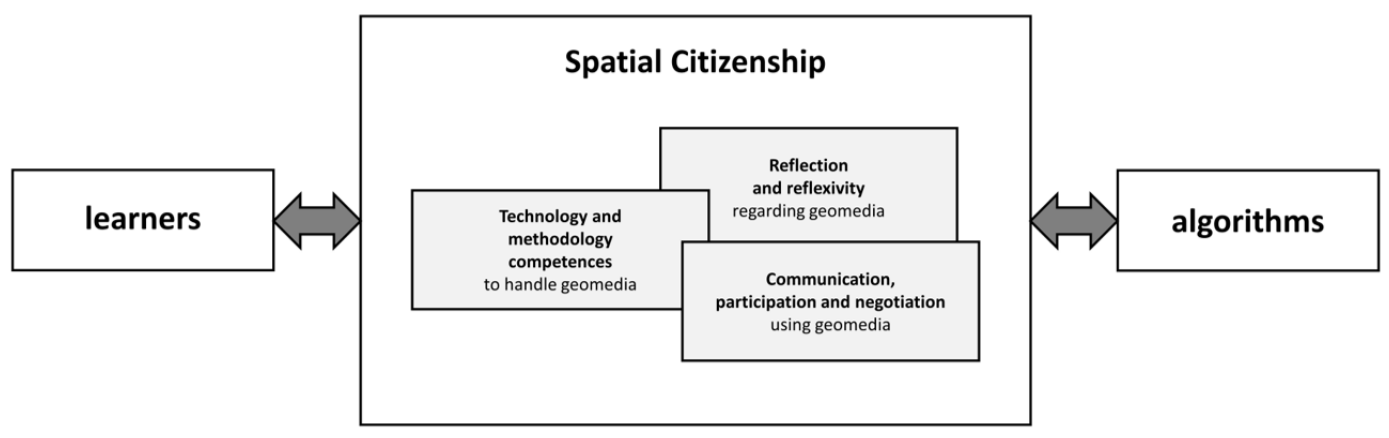

Figure 2: The Spatial Citizenship competence model as intervention between learners and algorithms (own figure based on Jekel et al. 2015: 7).

The competence model serves as the starting point for curriculum development for Spatial Citizenship in teacher education and training (Schulze et al., 2014a). The structure of the learning fields in this curriculum corresponds to the structure of the Spatial Citizenship competence model. Schulze et al. (2014b) formulated a description of particular learning outcomes for every single competence. In what follows, these descriptions are confronted with the theoretical conclusions presented above regarding algorithmic cultures. The Spatial Citizenship approach in our concept intervenes in the relationship between learners and algorithms (see Figure 2). The aim is to empower students to participate in spatial negotiation processes by reflecting on, and (where necessary) rejecting, algorithmic influence, and to use algorithms for their own purposes. At the same time, the Spatial Citizenship dimensions themselves are affected by algorithmic systems.

\section{Technology and methodology}

In the field of geomedia technology and methodology, geomedia must be seen as more than just instruments. By focusing on the use of geomedia, the interaction with algorithmic systems relativizes the relationship between individual and medium. A stronger orientation towards relational interactions with geomedia rather than the one-sided use of geomedia would be helpful. This does not exclude the use of geomedia to fulfil a certain purpose, but suggests a relation between media and individuals. For example, users react to the recommendations made by algorithmic systems when using navigation tools for sightseeing, either by visiting the suggested places or by ignoring the suggestions. Furthermore, the integration of machine learning systems in digital geomedia requires additional knowledge of how information is generated from geodata and about algorithmic mechanisms that serve to retrieve geoinformation.

\section{Reflection}

In the field of reflection, geomedia are predominantly seen as passive platforms and sites of negotiation (Schulze et al., 2014b: 370). Although a central focus is on the reflection of digital spatial constructions as products of actions, the view is limited to human or institutionalized actors (Schulze et al., 2014b: 370). In this context, algorithms are not considered as (partially) autonomous, space-constructing actors, as in the co-construction of places by users and algorithms on Instagram (Reithmeier \& Dorsch, 2021). Nevertheless, reflection encourages 
consideration of algorithms as configurators of spatially related practice by encompassing awareness of the influence of geomedia on everyday practices (Schulze et al., 2014b: 370).

\section{Communication}

This dimension emphasizes the relevance of specific digital competences and digital literacy for communication in digital environments. Here, reference is made to the social, actionoriented communication concept of language use as defined in the Common European Framework of Reference for Languages (Schulze et al., 2014b: 371). As algorithmic cultures are not specifically mentioned in this context, it depends on individual interpretation and the design of the curriculum whether algorithmic logic is referred to explicitly or not in an educational context. Furthermore, only other citizens and public authorities are mentioned as communication partners (Schulze et al., 2014b: 372). Algorithmic communication systems, such as social bots, are not mentioned as communication partners. However, learning outcomes that include reflections on socio-cultural aspects such as the structuring of one's own and other cultures can be found in the subordinate area of socio-linguistic competences (Schulze et al., 2014b: 373). These competences offer a starting point for discussing algorithmically-constructed realities and their reproduction in digital filter bubbles and echo chambers. In addition, we would like to suggest that the curriculum's understanding of communication could be expanded to include current and future technological aspects (e.g. bots).

\section{Spatial domain}

Within the spatial domain, the deconstruction of digital spatial constructions as products of power relations is envisaged (Schulze et al., 2014b: 375). In the context of algorithmic cultures, this offers opportunities to reflect on algorithmically-driven business models in social media and on the power of the platforms' operators. In addition, the spatial domain highlights the importance of digital constructions of space for the formation of social rules. The domain includes not only absolute but also relational concepts of space. Hence, the actions of human individuals are seen as spatially constitutive in the context of relational concepts of space. This can serve as a starting point for the discussion of algorithms as configurators of social practice. However, no attention is paid to algorithms as agents of infrastructure or to their constitutive influence on space and spatiality.

\section{Citizenship education domain}

The domain of citizenship education includes basic skills for negotiating the learners' roles within social structures (Schulze et al., 2014b: 377). In this context, as in the previous dimensions, geomedia are only mentioned as instruments for participation. In addition, a stronger focus in this domain should be placed on complex relationships, and algorithms should be seen as a constituting element of social relations.

\section{Implementation Strategies}

The dimension of didactic implementation strategies already contains many connectable points for implementation in the classroom. In many respects, it also takes the requirements of education of algorithm cultures into account. These include, for example, encouraging teachers to find educational opportunities to encourage students to engage independently with digital technologies (Schulze et al., 2014b: 379), and reflexive engagement with digital technologies in the context of educational processes inside and outside school (ibid.). Furthermore, the 
dimension includes reflection on one's competences concerning the design of educational processes. In designing a curriculum, one should focus explicitly on the influence of algorithmic cultures on the design of lessons, especially when using digital tools.

The analysis shows that Spatial Citizenship Education lends itself well to drawing on the content of algorithm cultures. Nevertheless, some adjustments have to be made to take into account the transformative power of algorithmic cultures in the educational process.

\section{Conclusion: There is still a long way to go}

The development of curricular documents is a permanent construction site, as new social, subject-specific, technical and educational developments must be taken into account continuously. To stimulate the discussion on algorithmic cultures and geography education processes, we have presented an analysis of the curriculum from Spatial Citizenship Education in relation to the discussion on algorithms and education. Our analysis has demonstrated that the Spatial Citizenship approach is a sound basis to do justice to the developments shown in the context of an algorithm culture. Nevertheless, algorithm cultures are accompanied by some changes in social and geographical structures that have not yet been captured by the approach. For example, the approach regards digital geomedia primarily as instruments used by individuals for participation. There is no consideration of geomedia as algorithmic, semiautonomous systems. This results in desiderata that should be addressed in a revision of the curriculum - for example, the competence to analyse the role of algorithms as configurators of social practices should be a part of the curriculum. ${ }^{1}$

The latest position paper of the Hochschulverband für Geographiedidaktik on the educational contribution of the subject of geography in a world shaped by digitalization and mediatization stresses the importance of this process: 'Geography education in a world shaped by mediatization [...] enables students to critically examine their role, the role of others and the significance of algorithms and artificial intelligence for the construction of identity, social realities and knowledge using geomedia' (Hochschulverband für Geographiedidaktik, 2020: 6, author's translation from German). However, against the backdrop of the traditional location of algorithms in mathematics and computer science education in schools, there have so far been few discussions about anchoring them in the context of social science subjects. But this is necessary to enable relational learning processes within algorithmic cultures, so that children and adolescents acquire the ability to develop digital sovereignty at an early stage. In this regard, appropriate media education also holds the potential for transforming the role of algorithms. Media education can help to initiate discussions about the effects of machine data analysis, to regulate or question algorithmically-supported business models, and to reveal and contain the power structures behind algorithmic systems (Kurz \& Rieger, 2017: 95). This can enable users to participate actively in shaping digital cultures and in negotiating the roles of algorithmic systems in the socio-material world.

\footnotetext{
${ }^{1}$ For a complete list of competences, see Fuchs 2021

(https://www.researchgate.net/publication/352680439_Algorithmuskulturen in der_geographischen B ildung (in German)).
} 
The various roles of algorithms as technical tools, agents and configurators of social practices demonstrate that to describe algorithms in dichotomous terms of social and technological determinism is inadequate. Even if the role definitions have more of an analytical character (and algorithms can be assigned different roles in practice - depending on the research question), they offer guidance for educational processes to clarify which type of algorithmic transition process takes place. These different aspects need to be further sharpened and differentiated in more in-depth considerations to make algorithmic cultures tangible for geography education on the content level. Algorithmic systems that move between two or three role tendencies and are therefore more difficult to grasp represent an exciting field for further discussions. Moreover, the normatively-developed requirements of education regarding algorithmic cultures should be examined for their practicability and relevance in the context of the learning process in the real-life classroom.

This paper is a small step towards a structured approach to the field of algorithmic cultures from geography education perspective. The theoretical lines of argumentation that emerge can be seen as an impetus for further reflection to supply the missing link of Spatial Citizenship Education.

\section{Acknowledgment}

The project 'Digi_Gap' is part of the 'Qualitätsoffensive Lehrerbildung', a joint initiative of the Federal Government and the Länder, which aims to improve the quality of teacher training. The programme is funded by the Federal Ministry of Education and Research. The authors are responsible for the content of this publication.

\section{References}

Allert, H., \& Richter, C. (2017). Kultur der Digitalität statt digitaler Bildungsrevolution. Pädagogische Rundschau, 71(1), 19-32.

Ash, J., Kitchin, R., \& Leszcynski, A. (2019). Introducing digital geographies. In Ash, J., Kitchin, R. \& Leszcynski, A. (Eds.): Digital Geographies. Los Angeles: SAGE. 1-10.

Couture, S., \& Toupin, S. (2019). What does the notion of 'sovereignty' mean when referring to the digital? New Media \& Society, 21(10), 2305-2322. doi:10.1177/1461444819865984

Brandt, M., C. J., Tucker, A., Kariryaa, K., Rasmussen, C., Abel, J., Small, J., Chave, L. V., Rasmussen, H., Pierre, A. A., Diouf, L., Kergoat, O., Mertz, C., Igel, F., Gieseke, J., Schöning, S., Li, K., Melocik, J., Meyer, S., Sinno, E., Romero, E., Glennie, A., Montagu, M., Dendoncker, \& Fensholt, R. (2020). An unexpectedly large count of trees in the West African Sahara and Sahel. Nature, 587, 78-82. doi:10.1038/s41586-020-2824-5

Dorsch, C., \& Kanwischer, D. (2020). Mündigkeit in einer Kultur der Digitalität: Geographische Bildung und ,Spatial Citizenship'. Zeitschrift für Didaktik der Gesellschaftswissenschaften, 11(1), 23-40.

Gillespie, T. (2016). \#trendingistrending: When Algorithms become Culture. In Seyfert, R., \& Roberge, J. (Eds.). Algorithmic Cultures. Essays on Meaning, Performance and New Technologies. London: Routledge, 52-75. 
Gryl, I., \& Jekel, T. (2012). Re-centering GI in secondary education: Towards a spatial citizenship approach. Cartographica, 47, 18-28.

Gryl, I., Dorsch, C., Lehner, M., Pokraka, J. \& Zimmer, J. (2020). Technologie, Medien, Mündigkeit: Integration autonomieförderlicher Haltungen und Kompetenzen in die fachliche Vermittlung. In Beißwenger, M., Bulizek, B., Gryl, I. \& Schacht, F. (Eds.). Digitale Innovationen und Kompetenzen in der Lehramtsausbildung. Duisburg: Universitätsverlag Rhein-Ruhr, 121-146.

Hochschulverband für Geographiedidaktik (2020). Der Beitrag des Fachs Geographie zur Bildung in einer durch Digitalisierung und Mediatisierung geprägten Welt. Positionspapier des Hochschulverbands für Geographiedidaktik (HGD) e.V.

Jekel, T., Gryl, I. \& Oberrauch, A. (2015). Education for Spatial Citizenship: Versuch einer Einordnung. GW-Unterricht, 137(1), 5-13. Retrieved from: http://www.gwunterricht.at/images/pdf/gwu_137_05_13_jekel_gryl_oberrauch.pdf

Jörissen, B., \& Marotzki, W. (2009). Medienbildung - eine Einführung. Theorie - Methoden Analysen. Stuttgart: UTB.

Kanwischer, D., \& Schlottmann, A. (2017). Virale Raumkonstruktionen - Soziale Medien und Mündigkeit im Kontext gesellschaftswissenschaftlicher Medienbildung. Zeitschrift für Didaktik der Gesellschaftswissenschaften, 8(2), 60-78.

Kitchin, R., \& Dodge, M. (2011). Code/Space. Software and Everyday Life. Cambridge, USA: MIT Press.

Krempl, S. (2020). Data Cities: Wie Hacktivisten Smart-City-Konzepte unterwandern. Retrieved from https://www.heise.de/news/Data-Cities-Wie-Hacktivisten-Smart-City-Konzepte-unterwandern4913295.html?utm_source=pocket-newtab-global-de-DE

Kurz, C. \& Rieger, F. (2017). Autonomie und Handlungsfähigkeit in der digitalen Welt. Crossing the creepy line? In Augstein, J. (Eds.): Reclaim autonomy. Selbstermächtigung in der digitalen Weltordnung. Berlin: Suhrkamp, 85-97.Patterson, J., \& Gibson, A. (2017). Deep Learning. Sebastopol: O'Reilly Media.

Rauer, V. (2016). Drones: The mobilization of algorithms. In Seyfert, R \& Roberge, J. (Eds.). Algorithmic Cultures. Essays on Meaning, Performance and New Technologies. London: Routledge, 140-157.

Reithmeier, C. \& Dorsch C. (2021). Soziale Medien. In Bork-Hüffer, T., Füller, H., \& Straube, T. (Eds.): Handbuch Digitale Geographien: Welt - Wissen - Werkzeuge. Stuttgart: UTB, 231-243.

Reithmeier, C., \& Kanwischer, D. (2020). Adolescents and the 'Instagramability' of Places - An Explorative Study on Spatial Practices in Social Media. GI_Forum, Journal for Geographic Information Science, 2, 96-106. doi: 10.1553/giscience2020_02_s96

Schulze, U., Gryl, I., \& Kanwischer, D. (2014a). Spatial Citizenship - Creating a Curriculum for Teacher Education. In Vogler, R., Car, A., Strobl, J., \& Griesebner, G. (Eds.): GI_Forum 2014. Geospatial Innovation for Society. Berlin: Herbert Wichmann Verlag, VDE Verlag GMBH, 230241. doi:10.1553/giscience2014s230

Schulze, U., Gryl, I., \& Kanwischer, D. (2014b). A Curriculum for Spatial Citizenship Education. In Vogler, R., Car, A., Strobl, J., \& Griesebner, G. (Eds.): GI_Forum 2014. Geospatial Innovation for Society. Berlin: Herbert Wichmann Verlag, VDE Verlag GMBH. 362-380. doi: 10.1553/giscience2014s362

Schulze, U., Gryl, I., \& Kanwischer, D. (2015). Spatial Citizenship education and digital geomedia: composing competences for teacher education and training. Journal of Geography in Higher Education, 39(3), 369-385. doi: 10.1080/03098265.2015.1048506

Seyfert, R., \& Roberge, J. (2016). What are algorithmic cultures? In Seyfert, R \& Roberge, J. (Eds.). Algorithmic Cultures. Essays on Meaning, Performance and New Technologies. London: Routledge. 1-25.

Stalder, F. (2018). The digital condition. Cambridge, UK: Polity. 